\title{
The Impact of Sports on Expressing One's Feelings
}

\author{
Didem Yavuz Söyler $^{1}$, M. Fatih Karahüseyinoğlu ${ }^{2}$, Oğuzhan Altungül ${ }^{2}$ \\ ${ }^{1}$ İnönü University Institute of Health Sciences Malatya, Turkey \\ ${ }^{2}$ Firat University Faculty of Sport Sciences, Elazig, Turkey \\ Correspondence: Oğuzhan Altungül, Firat University Faculty of Sport Sciences, Elazig, Turkey.
}

Received: February 21, 2017

doi:10.11114/jets.v5i4.2291

\author{
Accepted: March 16, $2017 \quad$ Online Published: March 20, 2017 \\ URL: https://doi.org/10.11114/jets.v5i4.2291
}

\begin{abstract}
The benefits of joining sports activities are quite many. Doing sports helps in socializing the individual by increasing the number of friends around the individual, and it also helps establishing an organized and disciplined life. Physical activities may also assist people to overcome aggression easily and express their feelings in a better way. This research aims at examining the impact of sports on expressing Firat University students' feelings based on different factors (age, gender, academic program). Screening model was applied to their search sample. Data collected from the students during the Fall Semester, 2015-2016. Their search sample included 175 students studying at Firat University. The emotion expressing's callused in this research was developed by Kingand Emmons (1990) as data collection tool to measure individuals' tendencies in expressing their feelings. Kuzucu (2006) adopted this scale to Turkish society. A 15item Likert-type questionnaire is designed to measure the tendencies in expressing emotions as positive, negative or warm feelings. Items score between 1 (Strongly Disagree) to 7 (Strongly Agree) where high scores in dictated high tendency in expressing feelings. In the scale, reverse-scoring is applied to item 6 and to item 14.The data obtained is analyzed using SPSS software. The independent samples t-test and one-way analysis of variance tests are used for data analyses purpose.
\end{abstract}

As result of there search, Sports Sciences Faculty students were ableto Express their feelings in a beter way than other faculties' students.

Keywords: sport, feelings of athletes, to express feelings

\section{Introduction}

It is indisputable that the sport is beneficial for human metabolism and nervous system. It has begun to take more places in our lives in recent years, not only because of our physical health but also because it is a process of expressing our mental health and our feelings.

Sport has an important role to play in the positive development of the individual's personality by ensuring the physical and mental health of the individual and in the life of the individual in the socialization process of the individual (Öztürk, 1982).

Sport is a vehicle for socializing individuals and allows them to express their emotions and realize themselves through the movements and games they host. It is stated that the individual drains many negative instincts and controls them, mainly through aggression (Fişek, 1980). With sports, the individual moves away from daily troubles. Somewhere physical and mental satisfaction is reached.

With the participation in sports events, people's circle of friends is expanding. In addition, when dealt with from the point of socialization, sporting events give people the skills of gaining respect, learning to fight, getting organized and disciplined, reducing aggression feelings and expressing their emotions (Öztürk, et all. 2007)

People's participation in the sport, and the development of their social characteristics, contribute to the development of social responsibility in humans. These include the development of emotional traits, the maintenance of psychological integrity, the development of the level of personal harmony, and the expression of emotions. Research findings on the psychological benefits of spore involvement in the literature also support this view (Bulgu, 2013). Thus, the socialization process of people is completed (Şahan, 2008). These include the development of emotional traits, the maintenance of psychological integrity, the development of the level of personal harmony, and the expression of 
emotions. Research findings on the psychological benefits of spore involvement in the literature also support this view (Peluso, et all. 2005; Salar, et all., 2012).

Gökdoğan's (1988) found that participating in sports activities increased the amount of discomfort, participated in positive psychological and social development of the adolescent, and satisfied with the body image. The level of satisfaction provided by the body is correlated with the adolescent self-confidence and interpersonal relationships. It facilitates fitness, physical activity, training the body, eliminating the difficulties of accepting the changed body and making it adapt to the changing body of the individual.

It has been found that in the research conducted in this respect, it is easier for those who play sports to live in a new situation than those who do not play sports, more outgoing, more hardworking, more patient, and ready to establish a social relationship.

\subsection{Expressing Feelings and Feelings}

In this section, information about emotions was given before moving on to the concept of expressing emotions. Psychology is a scientific discipline that aims to understand and explain human behavior. Emotions, such as thoughts and behaviors, are one of the areas on which psychology is most concerned. The word emotion derives from the word "emote" which means movement in Latin. We see in the most obvious way animals and children that emotions turn into action. Each sentiment in emotion repertoire has a unique role and effect. Strong emotions bring about significant changes (physiological signs) in our bodies. For example, it is obvious how a person who feels anger attacks the blood vessels in his hands. Fear also accelerates the heartbeat. In fact, all emotions are the basic elements that enable us to move. Emotion; a sense of emotion, and a certain set of specific thoughts, psychological and biological states and a set of motion tendencies (Goleman, 1996).

According to Dökmen (2000) emotions are the feelings that a person perceives at a certain moment, their feelings, the desires within his phenomenal field, and the exciting inner experiences.

Psychology is the most basic aim of science to recognize and understand. In this respect, the vast majority of studies in the field of psychology are carried out with this aim. At the beginning of this recognition and understanding work, it is important that the concept of "feeling" is well understood. The complexity of emotions, the differentiation of the causative agents, makes it difficult to identify the senses. Because emotion is just like a thrill, it reflects the mood of the person. The change and development in the mood of the person affects the emotions directly. Emotional words have different definitions because they have different meanings in writing language and spoken language.

The tendency to express emotions is described as spontaneous reflection of the internal state (King, \& Robert 1990). The person tends to shoot out emotions such as positive, negative, and intimacy (Graham, et al. 1981). Expressing emotions refers to the mental state or inner world (Kuzucu, 2006). Perceived, cognitive or emotional self-centered behavior in personal communications in everyday life also leads to a number of communication conflicts, such as hindering the establishment of warm relationships with people in the periphery (Dökmen, 2000). Expressing emotions is a great way of communicating with people around the world.

We may not express our feelings clearly for a variety of reasons, or we may not want to be open. In some cases, people may not know exactly what they are feeling. A father who exploits his child may claim to have love for his child, but may behave in a way that reflects distant feelings of compassion without being aware of it.

Even when we are aware of our feelings, sometimes we may underestimate the level of feeling we feel. We can say that we are "a bit worried" when we are experiencing intense panic in the face of an upcoming exam. Sometimes we can completely reject the negative feelings we are experiencing. For this reason, there may not be feelings that people feel many times they express. In such situations, it is often necessary to look at other elements that express emotion in order to better understand emotions (Morris, \& Hyun 2002).

Emotional expressions often occur in social relationships. Emotion expressions have two functions. The first is to give information and the second is to give emotion to the other side.

Many facial expressions and tone features reliably inform the recipient of the feelings and intent of the sender. For example, the shy and compelling attitude expressed by the sender makes the buyer more demanding about their willingness (Keltner, \& Cameron, 2000).

With regard to the second function, emotional behavior provides an opposite response to the emotional event and the environment. For example, a smile gives birth to a desire for rapport. The expression of anger leads to the formation of a fear response. The expression of sadness and stress generally induces sympathy, help, and the desire to approach that person on the other side. As a result, emotional expressions are an effective emotional stimulus that changes the emotional state, behavior and/or physiology of the other side (Bachorowski, \& Michael 2001; Rottenberg, \& Christine 2008). 
List another emotional expression tool. Individuals also express emotions and excitements with sounds. However, there is not yet a catalog compiling the vocal signs of various emotions and emotions. Usually, though not always, screaming, fear or amazement; Groaning, bitterness or misery; Sigh, sadness; Laughing is a pleasant occurrence. Vocalization or cut-off is extremely grieving; if it is violent, sharp and high-pitched, it is usually an indication of anger. Despite all this, it is difficult to differentiate emotions and emotions by looking at vocal expressions (Currie, et all., 2010).

Another means of conveying emotions is body movements. With our movements, with the state of our bodies, with our hand and arm behavior, we express our feelings, sometimes consciously, sometimes without being aware. These messages vary from culture to culture and from one social medium to another social medium. Movements vary according to age, community, sex, and the social environment we are in.

In short, studies have shown that the results obtained only by observing the expression of emotion or excitements are not reliable to the extent desired. There may not be consistency in the reactions people give to the same events. On the other hand, estimates of what is the sensation being expressed are correct only when we can see these expressions. The most accurate prediction for the feeling that is to be experienced or to be expressed is possible in environments where one can see the face expressions and gestures at the same time and at the same time be heard in the voice (Currie, et all., 2010).

\subsection{Emotion and Sex}

It is known that the males and females are different when it comes to feeling. But is this difference due to the fact that men are less emotional, or are men or women expressing their feelings in different ways? In a study by Eisenber and Lennon in 1993, it was found that women and men feel emotion physically at the same place, but women are more open to sharing or revealing when they hide the emotions they feel. It is influenced by the perception of emotions such as sadness, pain, compassion, and empathy as female emotions and the suggestion that men take their emotions out of their young age (Barrett, et all., 2000).

Hall emphasizes that women are more capable of expressing facial expressions, emotional responses, body movements, and altering their tone of voice than men (Hall, 1993).

\section{Methodology}

Expressing feelings the scale was developed by King and Emmons to measure the tendencies of individuals to express their feelings; the adaptation of the culture was carried out by Kuzucu. Based on likert type rating scale consisting of 16 items; Positive, negative, and intimidating emotions (Kuzucu, 2006). Scale items were created to include both positive and negative emotions. The items are scored between 1 and 7.1 indicates that the person did not fully participate in the item, and 7 indicate that he definitely participated. Alpha reliability coefficient of the Emotional Expression Scale. The high scores on the scale indicate that the tendency to express feelings is high.

Conversion of the survey findings to percentiles, frequencies, standard deviations, and mean value analyzes has been concluded by converting them to the recommendations in the light of the resulting scientific generalizations. 


\section{Results}

Table 1. Average points by independent variants distribution table

\begin{tabular}{llll}
\hline Gender & $\mathrm{n}$ & $\%$ & $\overline{\mathrm{x}}$ \\
\hline Male & 88 & 50.3 & 75.0114 \\
Woman & 87 & 49.7 & 76.5517 \\
\hline Active Sportsman & & & \\
\hline Yes & 44 & 12.7 & 85.3182 \\
No & 131 & 87.3 & 72.5725 \\
\hline Faculties & & & \\
\hline Humanities and Social Sciences & 25 & 14.1 & 70.5600 \\
Engineering Faculty & 25 & 14.1 & 69.8400 \\
Faculty of Education & 25 & 14.1 & 75.9200 \\
Faculty of Veterinary Medicine & 25 & 14.1 & 73.4800 \\
Health Services High School & 25 & 14.1 & 76.7200 \\
Faculty of Fisheries & 25 & 14.1 & 73.2400 \\
Faculty of Sport Sciences & 25 & 14.1 & 90.6800 \\
\hline Income rate & & & \\
\hline 1500and below & 131 & 74.0 & 73.3023 \\
1501 and 3000 & 40 & 24.0 & 76.5333 \\
3001and 5000 & 4 & 2.0 & 80.6667 \\
Total & 175 & 100 & 74.2486
\end{tabular}

Of the students who participated in the survey, $50.3 \%$ were male and $49.7 \%$ were female. There are a lot of people who say no to the question whether the participants are active sports. (87.3\%). A total of 175 people from all faculties participated in the survey. When the income level of the participants is examined, the majority (74\%) has an income level of 1500 TL or less.

Table 2. Mean values

\begin{tabular}{llllll}
\hline $\mathrm{n}$ & Average Point & $\mathrm{sd}$ & $\mathrm{t}$ & $\mathrm{df}$ & $\mathrm{p}$ \\
\hline 175 & 75.7771 & 15.53533 & 64.526 & 174 & 0.00 \\
\hline
\end{tabular}

The mean value of the students who participated in the study from the Emotion Expression Scale was shown on the table. As a result of the analyzes made, it was determined that the emotions were statistically significant when the expression scores were taken (mean; $75.77 \mathrm{p}<.01$ ).

Table 3. Mean and standard deviation of scores from emotions scales according to sport situations

\begin{tabular}{lllllll}
\hline Gender & $\mathrm{n}$ & Average Point & $\mathrm{sd}$ & $\mathrm{t}$ & $\mathrm{df}$ & $\mathrm{p}$ \\
\hline Male & 88 & 75.0114 & 14.96701 & \multirow{2}{*}{0.655} & 173 & 0.79 \\
Woman & 87 & 76.5517 & 13.13948 & & &
\end{tabular}

There was no statistically significant difference between male and female average scores. The scores of the girls and boys participating in the survey in this framework are very close to each other.

Table 4. Mean and standard deviation of scores received from emotions scale by faculty situations

\begin{tabular}{|c|c|c|c|c|c|c|}
\hline Faculty & $\mathrm{n}$ & Average Point & sd & $\mathrm{t}$ & $\mathrm{df}$ & $\mathrm{p}$ \\
\hline Other Faculty & 150 & 73.2933 & 15.23663 & \multirow{2}{*}{-5.617} & \multirow{2}{*}{173} & \multirow{2}{*}{0.00} \\
\hline Sports Science faculty & 25 & 90.6800 & 6.20967 & & & \\
\hline
\end{tabular}

There was a statistically significant difference between the scores of the Faculty of Sport Sciences and the Other Faculty $(\mathrm{p}<.01)$. Sports science faculty students were found to express their emotions better when compared to students in other faculties. 
Table 5. Average and standard of the points received from the emotion expression scale according to the situation of sports activities.

\begin{tabular}{lllllll}
\hline Doing sports & $\mathrm{n}$ & Average Point & $\mathrm{sd}$ & $\mathrm{t}$ & $\mathrm{df}$ & $\mathrm{p}$ \\
\hline Yes & 44 & 85.3182 & 12.05563 & \multirow{2}{*}{5.026} & \multirow{2}{*}{173} & 0.19 \\
No & 131 & 75.5725 & 15.29054 & & & \\
\hline
\end{tabular}

No statistically significant difference was observed between the Yes and No scores when participants' sporting situations were examined ( $\mathrm{p}<0.19)$.

\section{Discussion}

It is indisputable that the sport is beneficial for human metabolism and nervous system. It has begun to take more place in our lives in recent years, not only because of our physical health but also because it is a process of expressing our mental health and our feelings. 175 students attending Euphrates University in 2015-2016 attended. 88 of the students are male and 87 are female. There was no statistically significant difference between male and female average scores. The girls (75.01) and the boys (76.01) who participated in the survey in this framework are very close to each other.

When the findings of a research conducted by Yalçın (2010) were examined, it was found that the mean scores of female students were significantly higher than male students in terms of proximity subscale and positive emotional subscales. When the positive emotional subscores of female and male students 'appraisal scale were examined, the average scores of female students' intimacy (23.24); Male students' average scores (21.97) were found. As a result of the $\mathrm{t}$ test on whether the difference between the meanings is meaningful, the difference between them was found to be significant.

Selin (2012). made by the secondary schools in the provinces of Izmir, the province is forming 561 students continue. The mean of the tendency to express emotions is 71.64. This result is parallel to our work

A statistically significant difference was found between the scores of the Faculty of Sport Sciences and the other faculties in our study $(\mathrm{p}<01)$. Sports science faculty students (73.29) were found to express their emotions better when compared to students in the other faculties (90.68). A statistically significant difference was found between the subjects with Yes (85.31) and those without (75.57) ( $\mathrm{p}<0.01)$.

While Ugurlu and Şakar (2015) conducted a study, the universe was formed by university students and the sample consisted of 179 volunteer students, 90 male and 89 female selected by random system. The average age of the participants was 21.91 . While $30.7 \%$ of the participants did sports, $69.3 \%$ did not play sports. There appears to be a significant difference in the dimension of optimism / mood from emotional intelligence sub-dimensions. Male students' average scores for optimism are higher than female students. According to the sporting variables, the use of emotions and the evaluation of emotions from the emotional intelligence sub-dimensions were found to be significantly different in favor of women. According to the sporting variables, the use of emotions and the evaluation of emotions from the emotional intelligence sub-dimensions were found to be significantly different in favor of women.

We can say that emotional intelligence skills can be developed in sports. In a study of Kamin's (2000) American baseball players, a positive relationship was found between the performance statistics of these players and emotional intelligence.

In Costarelli's (2009) study of martial athletes and non-athletes, he said that athletes' emotional intelligence scores were higher than those who could not be athletes.

At the end of the literature review, a number of studies on expressing sport, personality, and feelings have been reached. In these studies, it is emphasized that sports have an important place in personality development. Furthermore, as a result of many studies, it has been determined that sports have positive effects on adverse factors such as anxiety and depression which affect not only the personality development but also the self-esteem development and the psychological well-being of the individual.

In a study of 57 tennis players at the national team level in England, it was understood that the tennis players were more outward oriented than those who did not play sports, but the most successful ones were inward characteristics (Tiryaki, 2000).

As a result; It has been revealed that the students studying at the Faculty of Sports Sciences better express their feelings from the students who read the other faculties. Nevertheless, it has also been seen with the studies that make sport make a positive contribution without expressing personality and emotions. 


\section{References}

Bachorowski, J. A., \& Owren, M. J. (2001). Not all laughs are alike: voiced but not unvoiced laughter readily elicits positive affect. Psychological Science, 12(3), 252-257. https://doi.org/10.1111/1467-9280.00346

Barrett, L. F. (2000). Sex differences in emotional awareness. Personality And Social Psychology Bulletin, 26(9), 1027-1035. https://doi.org/10.1177/01461672002611001

Bulgu, N. (2013). Social Benefits from Sport Participation: The Case of Students of Kazakhistan Ahmet Yesevi University. Hacettepe University Journal of Turkish Studies, Spring, (18), 25-45.

Costarelli, V., \& Dimitra, S. (2009). Emotional intelligence, body image and disordered eating attitudes in combat sport athletes. Journal of Exercise Science \& Fitness, 7(2), 104-111. https://doi.org/10.1016/S1728-869X(09)60013-7

Currie, C., \& Stamou, D. (2010). Social determinants of health and well-being among young people.health behaviour in school-aged children (hbsc) study: International Report From The 2009, 271.

Dökmen, Ü. (2000). Var olmak gelişmek uzlaşmak. İstanbul: Remzi Kitapevi.

Fişek, K. (1998). Devlet Politikası ve Toplumsal Yapıyla İlişkileri Açısından Türkiye'de ve Dünyada Spor Yönetimi. Ankara: Bă̆ırgan Yayımevi.

Gökdoğan, F. (1988). The level of body image satisfaction of secondary school students. Unpublished Master thesis. Ankara: Ankara University

Goleman, D. (1996). Vitallies, simple truths: the psychology of self-deception. Simon and Schuster.

Graham, J. W., Gentry, K. W., \& Green, J. (1981). The self-presentational nature of emotional expression: some evidence. Personality and Social Psychology Bulletin, 7(3), 467-474. https://doi.org/10.1177/014616728173016

Hall, P A. (1993). Policy paradigms, social learning, and the state: the case of economic policymaking in Britain. Comparative Politics, 275-296. https://doi.org/10.2307/422246

İşleroğlu S. (2012). Predictin subjective well-being among high school students according to self-esteem, social self efficacy and tendency to express of emotions. Unpublished Master thesis. İzmir: Ege University.

Kamin, D. (2000). The relationship between emotional intelligence levels and performance statistics of Ncaa division l-caliber baseball players. Souther Connecticut State University.

Keltner, D., \& Anderson, C. (2000). Saving face for drawing the functions and uses of embarrassment. Current Directions in Psychological Sciences, 9(6), 187-192. https://doi.org/10.1111/1467-8721.00091

King, L. A., \& Emmons, R. A. (1990). Conflict over emotional expression: psychological and physical correlates. Journal of personality and social psychology, 58(5), 864. https://doi.org/10.1037/0022-3514.58.5.864

Kuzucu, Y. (2006). The effects of psycho-education program of emotinal awareness and expression on levels of emotional awareness, tendency to express of emotions, psychological well-being and subjective well-being. Unpublished PhD thesis. Ankara: Ankara University.

Morris, S., \& Shin, H. S. (2002). Social value of publicin formation. The American Economic Review, 92(5), 1521-1534. https://doi.org/10.1257/000282802762024610

Öztürk, F., Efe, M., \& Koparan, Ş. (2007). The effect of handball training on social self-efficacy expectation and the assertiveness in the girls group of 14-16 years of age. Hacettepe Journal of Sport Sciences, 18(4), 147-155.

Öztürk, Ü. (1982). Orta dereceli okullarda beden eğitimi. Güven Matbaası, (s: 9).

Peluso, M. A. M., \& Andrade, L. H. S. G. D. (2005). Physical activity and mental health: the association between exercise and mood. Clinics, 60(1), 61-70. https://doi.org/10.1590/S1807-59322005000100012

Rottenberg, J., \& Vaughan, C. (2008). Emotion expression in depression: Emerging evidence for emotion context-insensitivity. In Emotion regulation (pp. 125-139) Springer US. https://doi.org/10.1007/978-0-387-29986-0_8

Şahan, H. (2007). The role of sports activities in the socialization process of university students. Unpublished $\mathrm{PhD}$ thesis. Konya: Selcuk University.

Salar, B., Hekim, M., \& Tokgöz, M. (2012). To com pare emotional state of individuals making team and individual sport 15-18 age group. Mehmet Akif Ersoy University Journal of Institute of Social Sciences, (6), 123-135.

Tiryaki, Ş. (2000). Spor Psikolojisi. Eylül Kitap ve Yayınevi., Ankara.

Uğurlu, F. M., \& Şakar M. (2015) Comparison of emotional intelligence and happiness levels of university students 
who are exercising and sedentary, The Journal of Academik Social Scienes, 3(17), 461-469.

Yalçın, S. B. (2010). Analyzing the ability of university students in expressing their emotions in terms of elexithymia and psychological necessities. Unpublished PhD thesis. Konya: Selçuk University.

\section{Copyrights}

Copyright for this article is retained by the author(s), with first publication rights granted to the journal.

This is an open-access article distributed under the terms and conditions of the Creative Commons Attribution license which permits unrestricted use, distribution, and reproduction in any medium, provided the original work is properly cited. 